
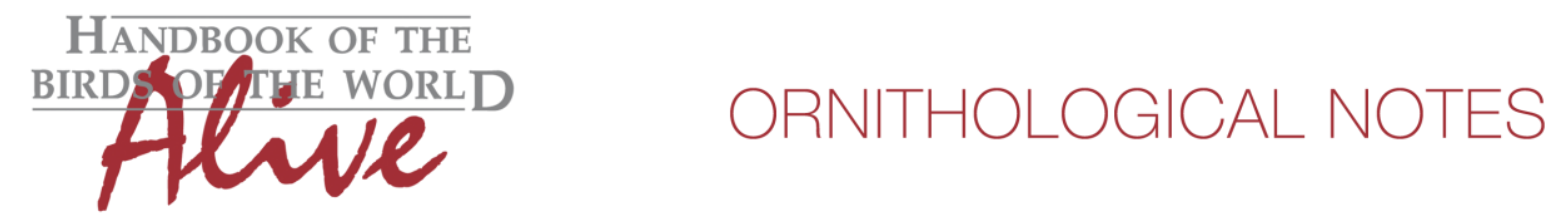

\title{
Notes on the vocalizations of Striated Antbird (Drymophila devillei)
}

Peter Boesman

In the following we briefly analyze and compare voice of the different races of Striated Antbird (Drymophila devillei). We also try to quantify the extent of any vocal differences using the criteria proposed by Tobias et al. (2010), as a support for taxonomic review. We have made use of sound recordings available on-line from Xeno Canto (XC).

A quick look at the sonograms of loudsong indicates there are vocal differences, but these are not necessarily linked to subspecies. We have measured a number of basic sound parameters for several groups. Within the subspecies devillei we can discern several vocally distinctive populations, which lead us to the following groups examined:

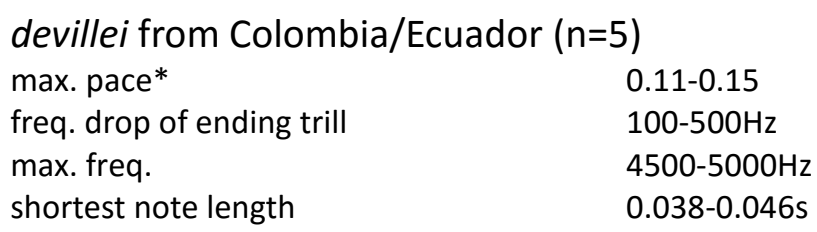

devillei (from C Bolivia) ( $\mathrm{n}=3$ )

max. pace

0.045-0.05

freq. drop of ending trill

$1400-1900 \mathrm{~Hz}$

max. freq.

$4400-5000 \mathrm{~Hz}$

shortest note length

0.016-0.024s

subochracea $(\mathrm{n}=5)$

max. pace

0.06-0.07s

freq. drop of ending trill

$1100-1700 \mathrm{~Hz}$

max. freq.

$4000-4700 \mathrm{~Hz}$

shortest note length

$0.02-0.028 \mathrm{~s}$

Birds of the isolated population in Colombia/Ecuador sing very much like devillei in the Amazon, with the song ending in a stuttering series of notes, at most slightly descending in pitch.

Birds of the race subochracea have a similar song, but notes end in a much faster trill which descends more in pitch. From the measurements shorter note length and larger frequency drop of the ending trill may lead to a score of resp. 2 and 2 (Fig. 1). 


\section{HANDBOOK OF THE

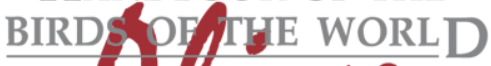 \\ Alve}

\section{ORNITHOLOGICAL NOTES}

However, presumed devillei birds from C Bolivia (not N Bolivia) seem to have a song very much like subochracea, also with a trilled descending end (XC2533) (!). Unless this makes sense morphologically, a larger sample set would have to confirm this apparent anomaly.
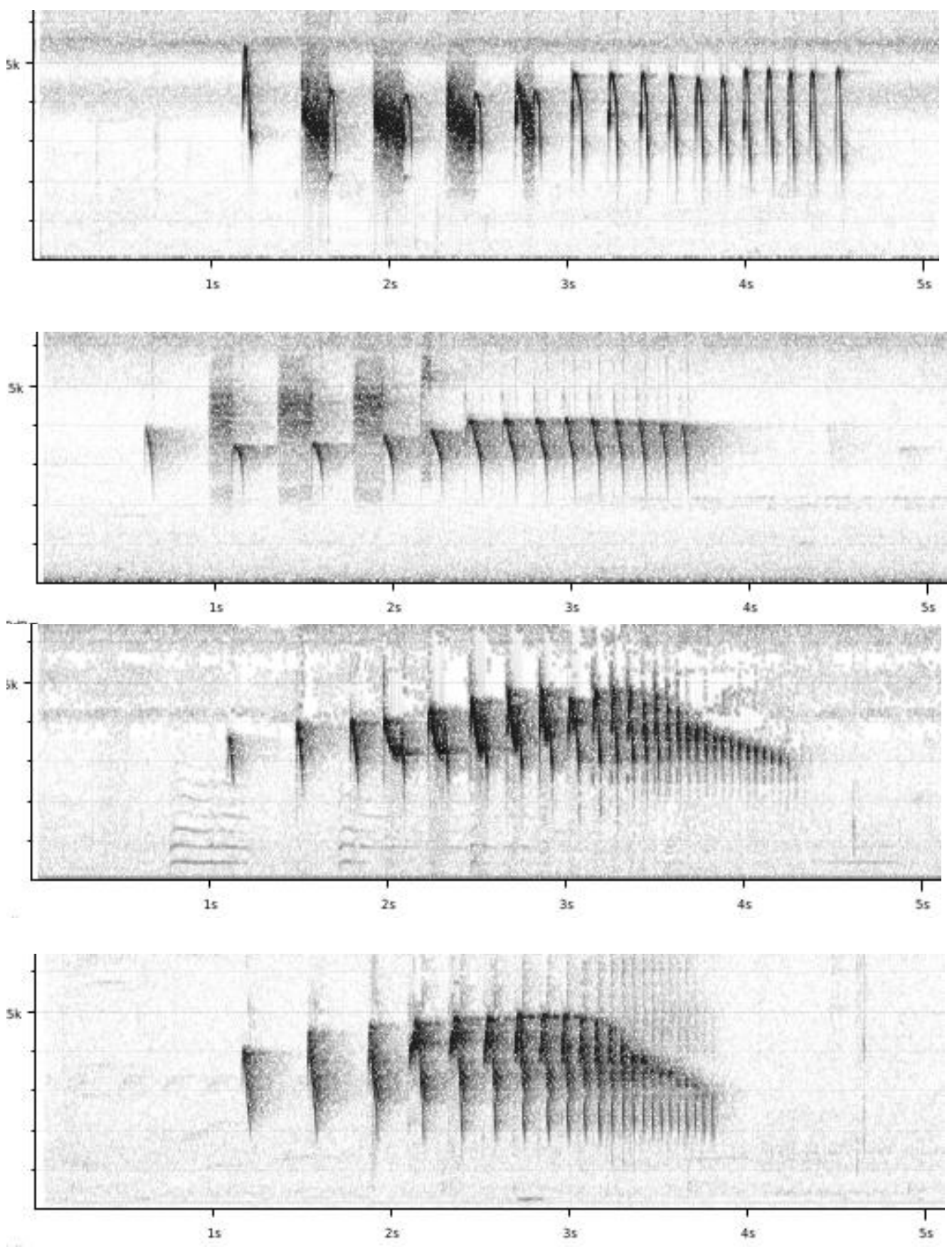

Figure 1: from top to bottom: devillei (Ecuador, SE Peru, C Bolivia), subochracea

Given that the vocal differences don't seem to match the present taxonomic treatment of subspecies, it seems safer not to score vocal differences until we have a larger set of recordings, especially from the SW Amazon region. 
This note was finalized on 6th May 2015, using sound recordings available on-line at that moment. We would like to thank in particular the sound recordists who placed their recordings for this species on XC: Roger AhIman, Nick Athanas, Peter Boesman, Tayler Brooks, Bradley Davis, David Geale, Niels Krabbe, Marcos A. Melo, Jeremy Minns, John V Moore, Jonas Nilsson, Sander Pieterse, Andrew Spencer, Joseph Tobias and Nathalie Seddon.

\section{References}

Tobias, J.A., Seddon, N., Spottiswoode, C.N., Pilgrim, J.D., Fishpool, L.D.C. \& Collar, N.J. (2010). Quantitative criteria for species delimitation. Ibis 152(4): 724-746.

\section{Recommended citation}

Boesman, P. (2016). Notes on the vocalizations of Striated Antbird (Drymophila devillei). HBW Alive Ornithological Note 57. In: Handbook of the Birds of the World Alive. Lynx Edicions, Barcelona. (retrieved from http://www.hbw.com/node/931937 on 30 April 2016). 